\title{
Downregulating a Type I Metacaspase in Petunia Accelerates Flower Senescence
}

\author{
Laura J. Chapin, Youyoun Moon ${ }^{1}$, and Michelle L. Jones ${ }^{2}$ \\ Department of Horticulture and Crop Science, The Ohio State University, Ohio Agricultural Research \\ and Development Center (OARDC), 1680 Madison Avenue, Wooster, OH 44691
}

\begin{abstract}
AdDitional IndEX wORDs. ethylene, flowers, petal senescence, Petunia $\times$ hybrida, programmed cell death
Abstract. Metacaspases are cysteine proteases from plants, fungi, and protozoans that have structural similarity to metazoan caspases. They play a critical role in programmed cell death (PCD) induced by developmental cues and environmental signals. In this study, a type I metacaspase (PhMC1) was identified and characterized from Petunia $\times$ hybrida 'Mitchell Diploid' (MD) (petunia). The recombinant PhMC1 had activity against the metacaspase substrate Boc-GRRAMC (GRR). Activity was highest at $\mathrm{pH} 7-9$ and was dependent on the active site $\mathrm{C}^{237}$. Quantitative polymerase chain reaction (qPCR) showed that $P h M C 1$ transcripts increased at a later stage of petal development, when corollas were visibly senescent in both pollinated and unpollinated flowers. Gene expression patterns were similar to that of the senescence-related gene PhCP10, a homolog of Arabidopsis thaliana (arabidopsis) AtSAG12. PhMC1 transcripts were upregulated in the petals by ethylene treatment. This ethylene regulation did not require protein synthesis, indicating that $P h M C 1$ is a primary ethylene response gene. Metacaspase-like activity against Boc-GRR-AMC increased in protein extracts from senescing petals. RNAi was used to knock down the expression of PhMC1. Transgenic PhMC1 petunias had no abnormal, vegetative growth phenotypes under normal greenhouse conditions, but flower senescence was accelerated by an average of 2 days.
\end{abstract}

Programmed cell death is a highly ordered process whereby plants or animals can remove unneeded or damaged cells or tissues during development or in response to abiotic or biotic stresses (Beers and McDowell, 2001). PCD in animals is characterized by the activation of a family of cysteine-dependent aspartate specific proteases or caspases. Caspases proteolytically activate downstream caspases or cleave substrates that ultimately lead to cell death (Fischer et al., 2003). The search for plant caspase-like enzymes led to the identification of a structurally related family of cysteine proteases called the metacaspases, which are also present in protozoans and fungi (Uren et al., 2000). Metacaspases have been shown to play a critical role in developmental and stress-induced PCD in plants (Fagundes et al., 2015; Lam and Zhang, 2012). Plant metacaspases may be positive or negative regulators of PCD, and they are classified as type I or type II (Coll et al., 2010). Type I metacaspases are distinguished by a proline- or glutamine-rich N-terminal prodomain containing a zinc finger motif. Type II metacaspases have no prodomain, but contain a linker between the p20 and p10 caspase-like domains. Whereas the caspases are aspartic acid-specific cysteine proteases, the metacaspases are cysteine proteases that cleave target substrates after arginine and lysine residues (Bozhkov et al., 2005; Tsiatsiani et al., 2013; Vercammen et al., 2004, 2006; Watanabe and Lam, 2005).

Characterization of gene expression patterns for multiple metacaspase family members has been conducted in arabidopsis

Received for publication 6 July 2017. Accepted for publication 14 Aug. 2017. This research was funded by an OARDC SEED Grant, The Ohio State University D.C. Kiplinger Endowment, and the Floriculture and Nursery Research Initiative. Salaries and research support were provided in part by State and Federal funds appropriated to the OARDC, The Ohio State University. Journal Article Number HCS 17-08.

${ }^{1}$ Current address: Division of Plant and Soil Science, West Virginia University, Morgantown, WV 26506.

${ }^{2}$ Corresponding author. E-mail: jones.1968@osu.edu.
(Kwon and Huang, 2013; Tsiatsiani et al., 2011), Vitis vinifera [grape (Zhang et al., 2013)], Oryza sativa [rice (Huang et al., 2015; Wang and Zhang, 2014)], Hevea brasiliensis [rubber tree (Liu et al., 2016a)], and Solanum lycopersicum [tomato (Liu et al., 2016b)]. The arabidopsis genome contains three type I and six type II metacaspases (Tsiatsiani et al., 2011), whereas the tomato genome has six type I and two type II metacaspases (Liu et al., 2016b). Expression analysis shows spatiotemporal regulation of individual metacaspase genes within the plant, as well as differential regulation by plant hormones, pathogens, and environmental stresses (Ahmad et al., 2012; Hoeberichts et al., 2003; Huang et al., 2015; Kim et al., 2013; Kwon and Huang, 2013; Liu et al., 2016a, 2016b; Tsiatsiani et al., 2011; Wang et al., 2012; Wang and Zhang, 2014; Zhang et al., 2013). Two type I metacaspases in arabidopsis, AtMC1 and AtMC2, work antagonistically to regulate cell death during the hypersensitive response (HR). AtMC1 is a positive regulator of HR-induced PCD, whereas AtMC2 functions as a negative regulator (Coll et al., 2010). Ethylene treatment induces multiple metacaspase genes in both rubber tree and tomato plants (Liu et al., 2016a, 2016b). Metacaspase genes have also been shown to be differentially regulated by abiotic stresses including cold, heat, drought, salt, ozone, and ultraviolet light (Ahmad et al., 2012; He et al., 2008; Huang et al., 2015; Kwon and Huang, 2013; Liu et al., 2016a, 2016b; Wang et al., 2012; Wang and Zhang, 2014).

Both plant development and adaptation to biotic and abiotic stresses require the induction of PCD to remove unwanted or unneeded cells and tissues. A recent study by Coll et al. (2014) reports a dual prodeath/prosurvival function for the type I metacaspase AtMC1. Although AtMC1 positively regulates pathogen-induced cell death in young tissues, it negatively regulates senescence in older tissues. The atmcl mutants exhibit premature leaf senescence, which is accompanied by earlier expression of the senescence marker AtSAG12 (Coll et al., 2014). These atmcl-deficient plants are also 
hypersensitive to reactive oxygen species (ROS), and they cannot restrict cell death after infection by pathogens.

Although cysteine proteases have been one of the most common proteins identified in screens for petal senescenceassociated genes (SAGs) (Jones et al., 2009), no studies to date have investigated the role of metacaspase proteases in petal senescence. This article presents the cloning and characterization of a type I metacaspase from petunia (PhMC1). Transgenic RNAi $P h M C 1$ petunias had reduced flower longevity, suggesting that $P h M C 1$ may function as a negative regulator of senescence in petals.

\section{Materials and Methods}

Cloning a metacaspase from petunia. Petunia sequences with similarity to the arabidopsis metacaspases were identified from BLAST searches of a petunia transcriptome database within the Sol Genomics Network [SGN (Fernandez-Pozo et al., 2015)]. Searches identified petunia clone PP-8-D05 as a putative metacaspase. The PP-8-D05 (PhMC1) insert cloned into pBluescript (Fermentas Intl., Burnie, MD) was obtained from the freezer stocks. Insert size analysis by gel electrophoresis and sequencing confirmed that the PhMCl clone was full length and contained the entire coding region.

The full length clone was sequenced [capillary sequencing, Molecular and Cellular Imaging Center, The Ohio State University/Ohio Agricultural Research and Development Center (OARDC), Wooster] to at least $6 \times$ coverage to assure accurate sequence data. Sequences were analyzed with ChromasPro (Technelysium, South Brisbane, Australia) and with the BLAST algorithm from the National Center for Biotechnology Information (NCBI, Bethesda, MD) nonredundant database (NCBI Resource Coordinators, 2017). Clustal Omega was used for multiple amino acid sequence alignments (Sievers et al., 2011). Coding regions of metacaspases from tomato (SlMC1 Solyc01g088710, S1MC2 Solyc03g094160, S1MC3 Solyc05g052130, SIMC4 Solyc01g105320, SIMC5 Solyc01g105300, SIMC6 Solyc01g105310, SIMC7 Solyc09g098150, and SIMC8 Solyc10g081300) and arabidopsis (AtMC1 AY322525, AtMC2 AY322526, AtMC3 AY322527, AtMC 4 AY322528, AtMC5
AY322532, AtMC6 AY322533, AtMC7 AY322529, AtMC8 AY322530, and AtMC9 AY322531) were obtained from SGN (Fernandez-Pozo et al., 2015) and NCBI (NCBI Resource Coordinators, 2017).

Construction of ReCombinant PRotein Mutants. The coding region of $P h M C 1$ was amplified by PCR using primers with BamHI and XhoI site extensions [mutagenesis primers PhMC1pET (Table 1)]. PCR fragments were ligated into the expression vector, pET28a(+) (Novagen, Darmstadt, Germany) at the BamHI and XhoI sites and transformed into Escherichia coli strain BL21(DE3) pLysS (New England Biolabs, Ipswich, MA). All constructs were verified by sequencing. Recombinant proteins that contained a mutation in the cysteine residue of the catalytic dyad were created using the QuikChange II sitedirected mutagenesis kit (Agilent, Santa Clara, CA). Cysteine was converted to alanine ( $\left.\mathrm{rPhMC} 1^{\mathrm{C} 237 \mathrm{~A}}\right)$. The entire coding region including the introduced mutation was then amplified using a set of primers with restriction enzyme extensions (Table 1). The PCR fragments were digested with the corresponding restriction enzymes, ligated into pET28a(+) vector, and transformed into E. coli strain BL21(DE3) pLysS (pET28a(+)::PhMC1 $\left.{ }^{\mathrm{C} 237 \mathrm{~A}}\right)$. All constructs were verified by sequencing.

Recombinant metacaspase enzyme aCtivity analysis. A single colony for each construct, including a control [E. coli with pET28a(+) vector alone] was picked and grown in $5 \mathrm{~mL}$ of Luria-Bertani (LB) liquid media containing kanamycin $\left(50 \mathrm{mg} \cdot \mathrm{mL}^{-1}\right)$ overnight at $37^{\circ} \mathrm{C}$. Three milliliters of overnight culture was inoculated in $50 \mathrm{~mL}$ LB with kanamycin and incubated at $37^{\circ} \mathrm{C}(3-3.5 \mathrm{~h})$ until $\mathrm{OD}_{600}$ was 0.6-1.0. Isopropyl $\beta$-D-1-thiogalactopyranoside was added to a final concentration of $1 \mathrm{~mm}$ and the cultures were incubated for $2-3 \mathrm{~h}$ at $37^{\circ} \mathrm{C}$ or up to $6 \mathrm{~h}$ at $30^{\circ} \mathrm{C}$. After the flasks were put on ice for $5 \mathrm{~min}$, the cells were harvested by centrifugation at $5000 \mathrm{~g}_{\mathrm{n}}$ for $5 \mathrm{~min}$ at $4{ }^{\circ} \mathrm{C}$. The cells were resuspended in a $0.25 \times$ volume of cold $20 \mathrm{~mm}$ Tris- $\mathrm{HCl} \mathrm{pH} \mathrm{8.0,} \mathrm{and} \mathrm{centrifuged} \mathrm{at} 5000 \mathrm{~g}_{\mathrm{n}}$ for $5 \mathrm{~min}$. Pellets were stored frozen at $-80{ }^{\circ} \mathrm{C}$, or purification was continued.

Metacaspases were purified according to the manufacturer's instruction using TALON Metal Affinity Resin (BD Biosciences Clontech, Mountain View, CA). The amount of purified

Table 1. Primers used for cloning and characterization of Petunia $\times$ hybrida metacaspase PhMC1.

\begin{tabular}{|c|c|c|}
\hline Primer name & Sequences & Notes \\
\hline$\overline{\text { F-PhMC1pET }}$ & AATTAGGATCCGACGGCAGGAGATACAAATGCAAGTG & Cloning PhMC1 into pET28a(+) \\
\hline $\mathrm{R}-\mathrm{PhMC} 1 \mathrm{pET}$ & TTATGAAGCTTGCAAACGTACCTGAGTTTCTTTGGCACC & \\
\hline F-PhMC1C237A & ACTGCCTTCAGTGGAACTTTCCTAGATTTGCCATTT & Introducing a point mutation at aa 237 of \\
\hline F-PhMC1 RT & AGGAGCCTCAACTATCCTCGTA & qPCR of $P h M C 1$ \\
\hline R-PhMC1 RT & CATGATCAAGGTTCACACAGAA & \\
\hline $\mathrm{R}-\mathrm{PhCP} 10 \mathrm{RT} 2$ & CCAAGCCTATCTCAATCCCATACA & \\
\hline F-PhACTIN RT & AGCCAACAGAGAGAAGATGACCCA & qPCR of Petunia actin, reference gene \\
\hline R-PhACTIN RT & ACACCATCACCAGAGTCCAACACA & \\
\hline F-PhRPS13 RT & CAGGCAGGTTAAGGCAAAGC & qPCR of Petunia RPS13, reference gene \\
\hline R-PhRPS13 RT & CTAGCAAGGTACAGAAACGGC & \\
\hline F-PhMC1RNAi & TGGAACACTAGTGGCGCGCCGCGATGGAGATGAGGTTGAT & Creating RNAi construct \\
\hline
\end{tabular}


metacaspase was quantified using the Bradford Protein Assay (Bio-Rad, Hercules, CA). The purified recombinant protein $(0.1 \mu \mathrm{g})$ and $100 \mu \mathrm{M}$ peptidyl substrates or inhibitors were mixed in $100 \mu \mathrm{L}$ of reaction buffer [150 mM NaCl, $10 \mathrm{~mm}$ $\mathrm{CaCl}_{2}, 10 \%$ glycerol (w/v), 0.1\% CHAPS, $10 \mathrm{~mm}$ DTT, and $\mathrm{pH}$ adjustment agents]. The $\mathrm{pH}$ of the reaction buffers was adjusted with $100 \mathrm{~mm}$ glycine (pH 4 and $\mathrm{pH} 5), 100 \mathrm{~mm} \operatorname{MES}(\mathrm{pH} 6)$, $50 \mathrm{~mm}$ HEPES-KOH (pH 7 and $\mathrm{pH}$ 8), or $100 \mathrm{~mm}$ Tris (pH 9) for optimum $\mathrm{pH}$ analysis. All other substrate and inhibitor assays were conducted at $\mathrm{pH}$ 8. The reaction mix containing $50 \mu \mathrm{M}$ of the metacaspase substrate $t$-butyloxycarbonyl-Gly-ArgArg-7-amido-4-methylcoumarin (GRR, lot no. 0519975; Bachem, Torrance, CA) or the caspase substrate Asp-GluVal-Asp-7-amido-4-methylcoumarin (Ac-DEVD-AMC, lot no. 2000367; Bachem) was incubated for $30 \mathrm{~min}$ at $30{ }^{\circ} \mathrm{C}$. One hundred microliters of $10 \%$ acetic acid in $150 \mathrm{~mm}$ sodium acetate was added to stop the reaction. A $30-\mu \mathrm{L}$ aliquot of the reaction mix was diluted with nanopure water to $1.5 \mathrm{~mL}$.

Enzyme activity was measured as the amount of AMC liberated using a fluorescence spectrophotometer (DTX880 Multimode Detector; Beckman Coulter, Indianapolis, IN) at $370 \mathrm{~nm}$ excitation and $450 \mathrm{~nm}$ emission wavelengths. Substrates included GRR and Ac-DEVD-AMC, and inhibitors included $10 \mathrm{~mm}$ iodoacetamide and $1 \mu \mathrm{M}$ leupeptin (SigmaAldrich, St. Louis, MO). All reactions were performed in triplicate and data were analyzed using Multimode Analysis Software (version 3.2.0.6, Beckman Coulter).

Metacaspase-like aCtivity in petunia corollas. Protein was extracted from corolla samples by methods previously reported (Watanabe and Lam, 2011) and quantified with Pierce Coomassie Protein Assay Reagent (Thermo Fisher Scientific, Waltham, MA). Metacaspase activity against GRR substrate was assayed as described previously using $50 \mathrm{~mm}$ HEPES-KOH $\mathrm{pH}$ 8.0. Fluorescence units measured at 370-nm excitation and 450-nm emission wavelengths after a $10-\mathrm{min}$ incubation at $30{ }^{\circ} \mathrm{C}$ are reported.

Plant materials. Petunia $\times$ hybrida $\mathrm{MD}$ were started from seed and grown in the greenhouse at the OARDC unless otherwise noted. The growing environment was $24 / 20{ }^{\circ} \mathrm{C}$ (day/night) with a 13-h photoperiod supplemented by highpressure sodium and metal halide lights (GLX/GLS e-systems GROW lights; PARSource, Petaluma, CA). Plants were fertilized at each irrigation with $20 \mathrm{~N}-1.3 \mathrm{P}-15.8 \mathrm{~K}$ (Jack's Professional Petunia FeED; J.R. Peters, Allentown, PA) at $150 \mathrm{mg} \cdot \mathrm{L}^{-1} \mathrm{~N}$.

Flower development and ethylene treatments. Petunia flowers were tagged and emasculated $1 \mathrm{~d}$ before flower opening (i.e., anthesis) to prevent self-pollination. Corollas from unpollinated flowers were collected every day from anthesis $(0 \mathrm{~d})$ to senescence $(7 \mathrm{~d})$ to investigate gene expression during petal development. Six corollas were collected from at least three different plants at $1000 \mathrm{HR}$ each day. To study pollinationinduced responses, flowers were pollinated on the day of anthesis, and corollas were collected at 0, 1, 3, 6, 12, 18, 24, and $48 \mathrm{~h}$ after pollination $(n=6)$. For ethylene and cycloheximide treatments, flowers that were at $1 \mathrm{~d}$ after anthesis were detached from the plants, and peduncles were cut to equal lengths. Peduncles were placed in vials of $0 \mu \mathrm{M}$ (nanopure $\mathrm{H}_{2} \mathrm{O}$ ) or $50 \mu \mathrm{M}$ cycloheximide for $3 \mathrm{~h}$. After cycloheximide treatment, flowers (all in vials of $\mathrm{H}_{2} \mathrm{O}$ ) were placed into sealed 24-L chambers. The chambers were injected with ethylene to a final concentration of $0,0.1,1.0$, or $10.0 \mu \mathrm{L} \cdot \mathrm{L}^{-1}$. Six flowers were included in each treatment. The chamber with $0 \mu \mathrm{L} \cdot \mathrm{L}^{-1}$ was the control chamber and included a sachet containing potassium permanganate to absorb any ethylene produced by the flowers. After $4 \mathrm{~h}$, the chambers were opened, and the corollas were collected for subsequent RNA extraction.

RNA EXTRACTION AND GENE EXPRESSION ANALYSIS BY QUANTITATIVE PCR. All collected tissue was immediately frozen in liquid nitrogen and stored at $-80{ }^{\circ} \mathrm{C}$ before RNA extraction. Plant tissue was ground to a fine powder in liquid nitrogen, and total RNA was isolated using TRIzol Reagent (Invitrogen, Carlsbad, CA). RNA was treated with RQ1 RNase-free DNase (Promega, Madison, WI), and cDNA was synthesized from $2 \mu \mathrm{g}$ RNA using the Omniscript Reverse Transcriptase kit (Qiagen, Valencia, CA). A qPCR was performed in a $20-\mu \mathrm{L}$ reaction volume using SYBR Green Supermix (Bio-Rad). One microliter cDNA was used as template, and all reactions were performed in triplicate. PCR was conducted for 40 cycles of $94^{\circ} \mathrm{C}$ for $10 \mathrm{~s}, 62^{\circ} \mathrm{C}$ for $30 \mathrm{~s}$, and $72^{\circ} \mathrm{C}$ for $30 \mathrm{~s}$ using a thermocycler (iQ5, Bio-Rad). Primers specific to PhMC1 and PhCP10 [PhMC1 RT, PhCP10 RT (Table 1)] were designed using IDT SciTools (PrimerQuest; Integrated DNA Technologies, Coralville, IA). Amplification specificity was confirmed with melt curve analysis. Normalized relative quantitation was calculated using arithmetic mean of relative quantity for each target gene with PhACTIN (CV299322) and PhRPS13 (SGN-U209515) as reference genes (Hellemans et al., 2007). These genes have been previously determined to serve as reference genes in petunia flower tissue (Chapin and Jones, 2009; Mallona et al., 2010).

PhMC1 RNAi transgenic petunias. PhMCl was downregulated using RNAi in transgenic petunias. For RNAi constructs, PCR products from the PhMCl coding region [a 450-bp fragment from 563 to 1013 bp; primers F-PhMC1RNAi and R-PhMC1RNAi (Table 1)] were ligated in the inverted orientation flanking the GUS stuffer region in the pGSA1276 binary vector containing a kanamycin-resistance selectable marker. PCR fragments of PhMC1 were ligated at the AscI and SwaI sites in the sense orientation and at the BamHI and SpeI sites in the antisense orientation. Leaf pieces $(1 \times 1 \mathrm{~cm})$ of $P$. hybrida MD were transformed with pGSA1276::PhMC1 using Agrobacterium tumefaciens LBA4404 following the method of Jorgensen et al. (1996). A leaf was collected from each resulting plantlet for PCR verification of successful transformation. The primers for PCR verification [F-PhMC1RNAi2 and R-PhMC1RNAi2 (Table 1)] contained an intron to distinguish between the endogenous gene and the transgene. Plants positive for the transgene and with decreased expression of PhMCl as compared with wild type MD were selected to carry on to the next generation. Plants were self-pollinated and seeds were collected to generate $T_{1}$ and then $T_{2}$ plants. $T_{2}$ plants from three independent transformation events (line F05-53, F05-6, and F05-65) were used in all experiments. Three flowers per plant, from five plants per line, were emasculated and tagged as previously described $(n=15)$. Flower longevity was measured as the number of days from anthesis until unpollinated flowers were visibly wilted. Flowers for longevity evaluations and RNA extraction were collected in April, and the greenhouse temperatures during this collection averaged $22.6 \pm 2.0 / 18.6 \pm 2.7^{\circ} \mathrm{C}$ (day/night). The expression of PhMC1 was compared between transgenic and wild type corollas at $48 \mathrm{~h}$ after pollination. Flowers were pollinated on the day of flower opening with pollen from another flower on the same plant. RNA extraction and gene expression analyses were 
conducted as described in previous sections. Greenhouse experiments used a completely randomized design and plants were grown under the conditions described previously. All experiments with transgenic plants were repeated at least twice.

Statistical analysis. Enzyme activity, flower longevity, and gene expression were analyzed in SAS (version 9.3; SAS Institute, Cary, NC) using the Proc GLIMMIX (generalized linear mixed model) algorithm with least squared means separation evaluated at $P \leq 0.05$.

\section{Results}

PhMC1 is a type I metacaspase. PhMCl (GenBank accession no. JQ314004) included an open reading frame of $1044 \mathrm{bp}$ and encoded a protein with 347 aa and a predicted MW of $38.2 \mathrm{kDa}$. Alignment of the predicted aa sequence of PhMC1 with other metacaspases (Supplemental Fig. 1) indicated that the highly conserved signature histidine/cysteine dyad of caspases was present in the petunia clone. PhMC1 contained a 90 amino acid N-terminal prodomain, which is characteristic of the type I metacaspases (Supplemental Fig. 1). This prodomain contained one plant-specific $L S D 1$-like zinc finger motif defined by the sequence CxxCRxxLMYxxGASxVxCxxC. The prodomains of the arabidopsis metacaspases were proline (AtMC1 and AtMC2) or glutamine (AtMC3) rich, whereas the $\mathrm{PhMC} 1$ prodomain did not contain either a proline or a glutamine rich region. Among the tomato and arabidopsis metacaspases, PhMC1 shares the highest amino acid identity with SIMC6 (77.98\%) and AtMC1 (52.6\%), respectively (Table 2). These are both type I metacaspases.

Recombinant PhMC1 has metacaspase-like aCtivity. Purified recombinant metacaspases were incubated with a metacaspase substrate, the synthetic, fluorogenic oligopeptide P1 arginine GRR, or a caspase substrate Ac-DEVD-AMC (DEVD). The enzyme activity was determined by measuring the amount of fluorescence generated by the release of $\mathrm{AMC}$, and relative

Table 2. Comparison of the percent amino acid identity between arabidopsis and tomato metacaspases and petunia metacaspase 1 (PhMC1).

\begin{tabular}{lc}
\hline Metacaspase & Identity $(\%)^{z}$ \\
\hline SIMC6 & 77.98 \\
SIMC5 & 73.73 \\
AtMC1 & 52.60 \\
SIMC1 & 50.64 \\
SIMC2 & 48.87 \\
AtMC3 & 47.29 \\
SIMC3 & 45.66 \\
AtMC2 & 43.07 \\
SIMC4 & 36.81 \\
AtMC5 & 33.90 \\
AtMC4 & 33.47 \\
AtMC6 & 32.77 \\
SIMC7 & 32.77 \\
AtMC7 & 30.77 \\
AtMC9 & 29.87 \\
SIMC8 & 29.60 \\
AtMC8 & 29.36 \\
\hline
\end{tabular}

${ }^{\mathrm{z}}$ Percent identity was obtained from a pairwise comparison of amino acid sequences using Clustal Omega (Sievers et al., 2011).
A
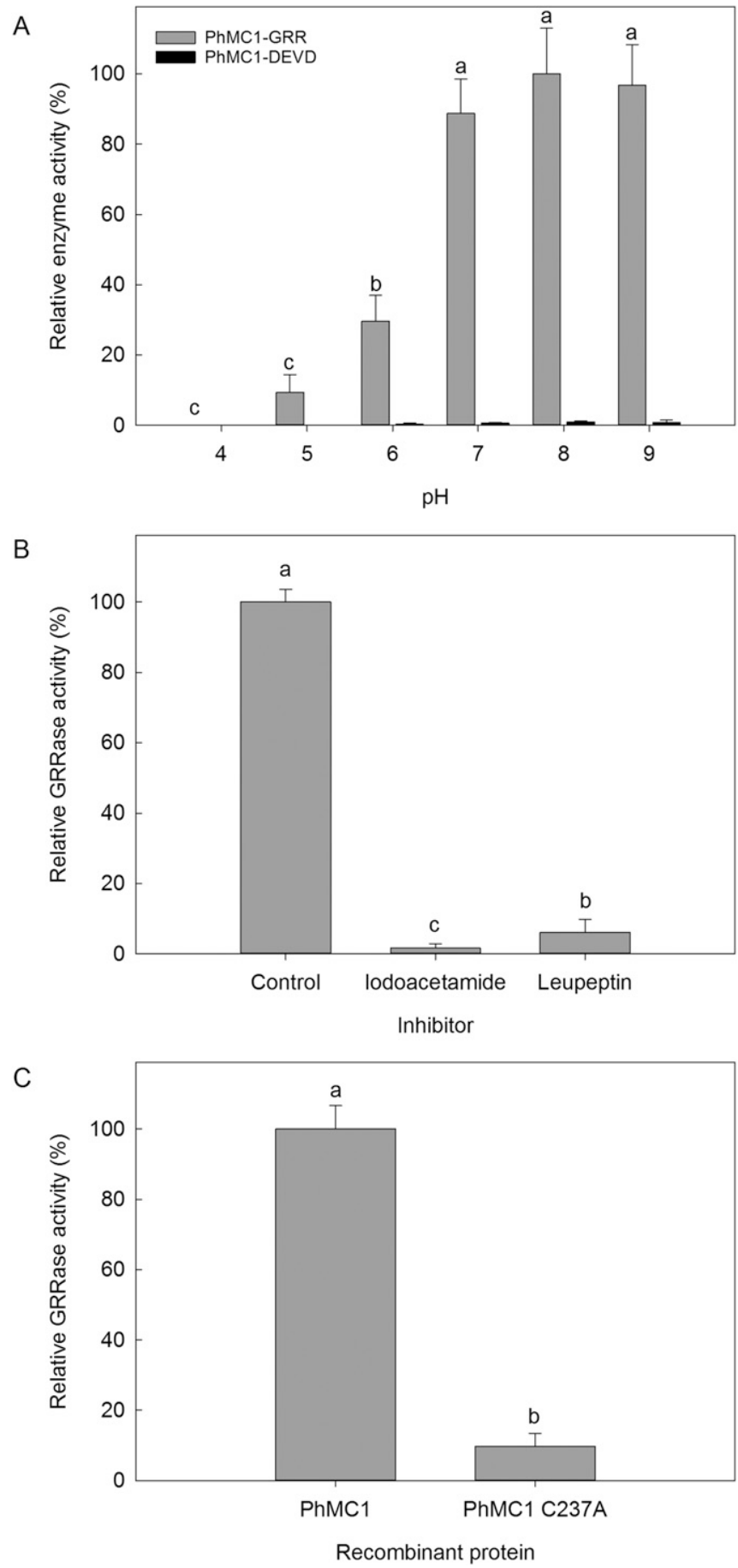

Fig. 1. Characterization of substrate specificity and $\mathrm{pH}$ optima for Petunia $\times$ hybrida metacaspase 1 (PhMC1). Relative enzymatic activity in each sample is presented as the percentage of the activity compared with the sample with the highest activity. All data are the means of three replicates $\pm \mathrm{SE}(n=3)$. The experiment was performed twice with similar results. Different letters represent statistically significant difference between the means $(P \leq 0.05)$. (A) The activity of the recombinant PhMC1 against the fluorogenic metacaspase substrate Boc-GRR-AMC (GRR) and the fluorogenic caspase substrate Ac-DEVD-AMC (DEVD) was determined at various $\mathrm{pH}$. (B) The effect of cysteine protease inhibitor (iodoacetamide) and arginal protease inhibitor (leupeptin) on the activity of recombinant PhMC1 using GRR as substrate was evaluated at $\mathrm{pH}$ 8.0. All GRRase activity of the recombinant metacaspases in the presence of inhibitors is expressed as a percentage of the relative activity without inhibitors. (C) A recombinant metacaspase mutant, $\mathrm{PhMC1} 1^{\mathrm{C} 237 \mathrm{~A}}$, was created with the catalytic cysteine converted to alanine. The activity of this mutant was determined using the substrate GRR at pH 8.0. 

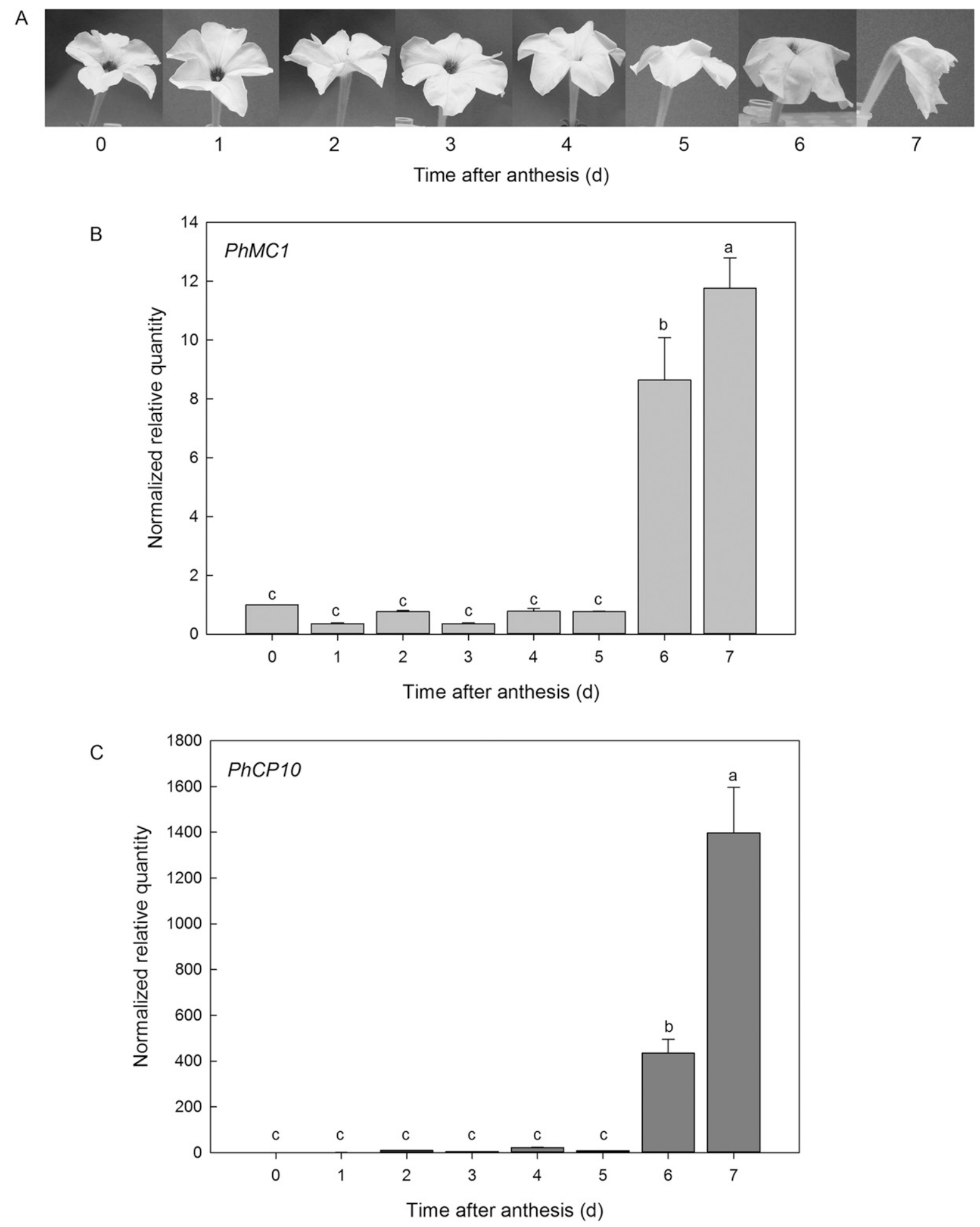

Fig. 2. Gene expression was analyzed in petals of unpollinated Petunia $\times$ hybrida 'Mitchell Diploid' flowers. (A) Photos show flowers from anthesis ( $0 \mathrm{~d})$ through senescence and corolla wilting ( $7 \mathrm{~d})$. Numbers indicate the days after anthesis. Transcript levels of $(\mathbf{B}) P h M C 1$ and $(\mathbf{C}) P h C P 10(\mathrm{mean} \pm \mathrm{SD}, n=3)$ in petals during flower development. Relative mRNA abundance compared with two reference genes (PhACTIN and PhRPS13) was determined by reverse transcription quantitative polymerase chain reaction. Different letters represent statistically significant difference between the means $(P \leq 0.05)$.

enzymatic activities were calculated as the percentage of activity compared with the sample with the highest metacaspase activity. E. coli BL21 (DE3) containing only the control vector $\mathrm{pET} 28 \mathrm{a}(+)$ was used to determine background activity with both substrates. PhMC1 cleaved the GRR substrate containing an arginine residue at the P1 position (Fig. 1A). There was barely detectable activity against the caspasespecific substrate (DEVD) containing an aspartic acid residue at the P1 position. The petunia metacaspase had optimal GRRase activity at $\mathrm{pH} 7$ to 9 . Iodoacetamide (10 mM), 
a cysteine protease inhibitor, and leupeptin $(10 \mu \mathrm{M})$, an arginal protease inhibitor, resulted in near complete inhibition (about 95\% and $90 \%$, respectively) of all GRRase activity (Fig. 1B). Recombinant mutants that had the putative catalytic cysteine replaced with an alanine $\left(\mathrm{rPhMC1}{ }^{\mathrm{C} 237 \mathrm{~A}}\right)$ were used to determine if the conserved cysteine was required for GRRase activity. The GRRase activity of PhMC1 was nearly abolished when the catalytic site cysteine was mutated (Fig. 1C).

PhMC1 Gene EXPRESSION IS UPREGULATED DURING PETAL SENESCENCE AND BY ETHYLENE. Quantitative PCR data indicated that $P h M C 1$ gene expression was upregulated in flower petals (Figs. 2 and 3). Expression of PhMCl was low in unpollinated petals from 0 to $5 \mathrm{~d}$ after anthesis and increased during senescence ( 6 and $7 \mathrm{~d}$ after anthesis) when the petals were visibly wilted (Fig. 2A and B). PhCP10, a homolog of arabidopsis $S A G 12$, which is often used as a senescence marker (Jones et al., 2005; Noh and Amasino, 1999), was also upregulated at 6 and $7 \mathrm{~d}$ (Fig. 2C). In petunia flowers, pollination accelerates petal senescence. PhMC1 was also upregulated in petals from pollinated flowers at $48 \mathrm{~h}$ when the corollas were visibly wilted (Fig. 3A and B). Increases in PhCP10 transcript abundance were detected at $24 \mathrm{~h}$ after pollination when corollas were not yet visibly wilted and continued to increase at $48 \mathrm{~h}$ (Fig. 3C). PhMCl transcript abundance also increased in the petals when detached flowers were treated with ethylene (Fig. 4A). There was no effect of treatment with $0.1 \mu \mathrm{L} \cdot \mathrm{L}^{-1}$ ethylene for $4 \mathrm{~h}$, but transcript abundance increased 4.5-fold when flowers were treated with $1.0 \mu \mathrm{L} \cdot \mathrm{L}^{-1}$ ethylene. Gene expression continued to increase slightly (though not significantly) with the $10 \mu \mathrm{L} \cdot \mathrm{L}^{-1}$ treatment. Cycloheximide treatment did not prevent or reduce the increases in PhMC1 transcript abundance induced by ethylene treatment. Transcript abundance of $\mathrm{PhCP} 10$ in petals also increased 27.7-fold with $1.0 \mu \mathrm{L} \cdot \mathrm{L}^{-1}$ ethylene treatment compared with untreated control flowers, but this induction was less with $10 \mu \mathrm{L} \cdot \mathrm{L}^{-1}$ ethylene treatment (Fig. 4B). In contrast to PhMC1, cycloheximide treatment significantly inhibited the ethyleneinduced increase in expression of $P h C P 10$.
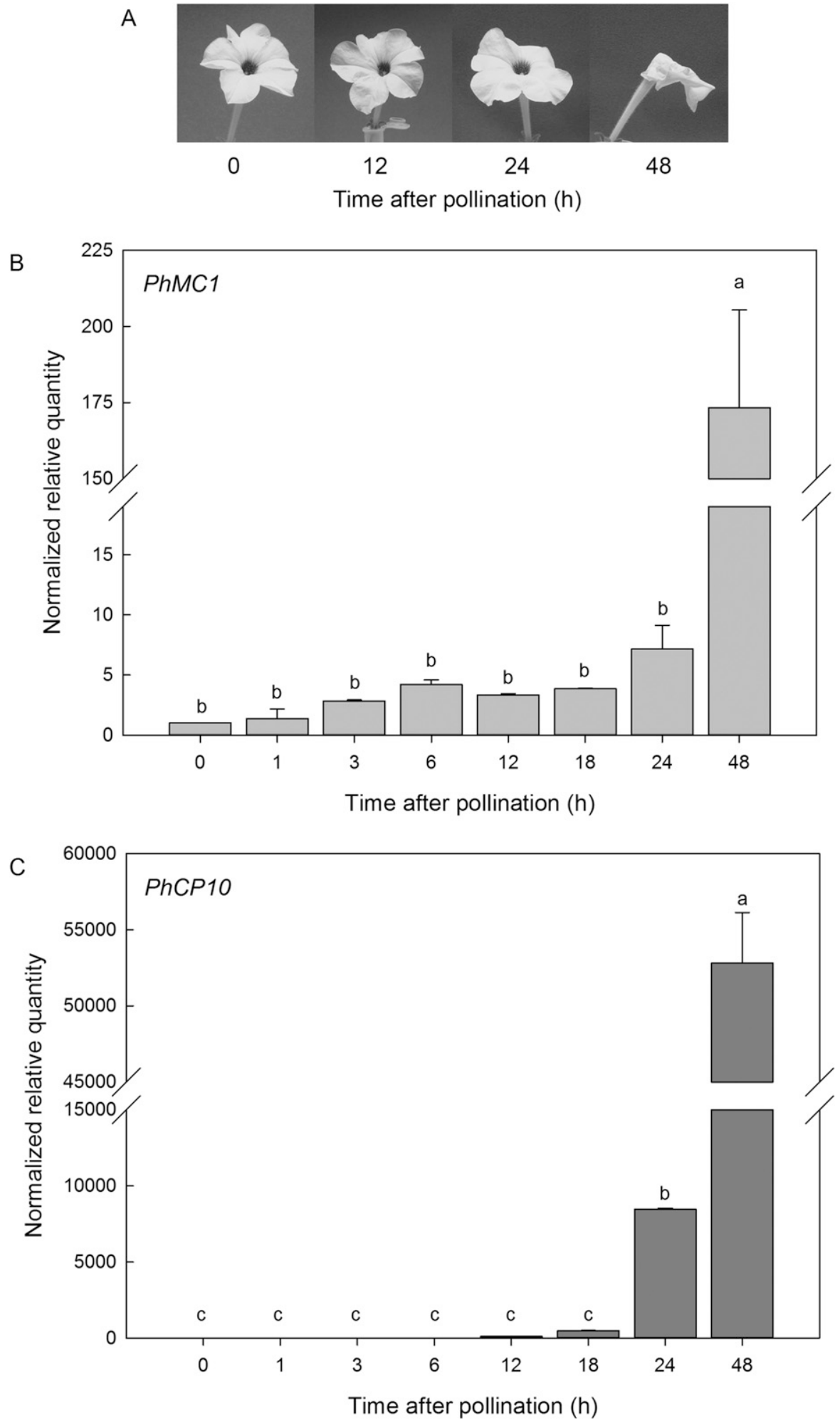

Fig. 3. Gene expression was analyzed in petals of pollinated Petunia ×hybrida 'Mitchell Diploid' flowers. (A) Photos show flowers at 0, 12, 24, and $48 \mathrm{~h}$ after pollination. Transcript levels of (B) PhMCl and (C) PhCP10 (mean $\pm \mathrm{SD}, n=3$ ) in petals from pollinated flowers. Relative mRNA abundance compared with two reference genes (PhACTIN and PhRPS13) was determined by reverse transcription quantitative polymerase chain reaction. Different letters represent statistically significant difference between the means $(P \leq 0.05)$.

MetaCAPASE-Like aCtivity inCREASES in SENESCING PETAls. The GRR substrate was used to measure metacaspase-like activity in petal protein extracts from newly open flowers 

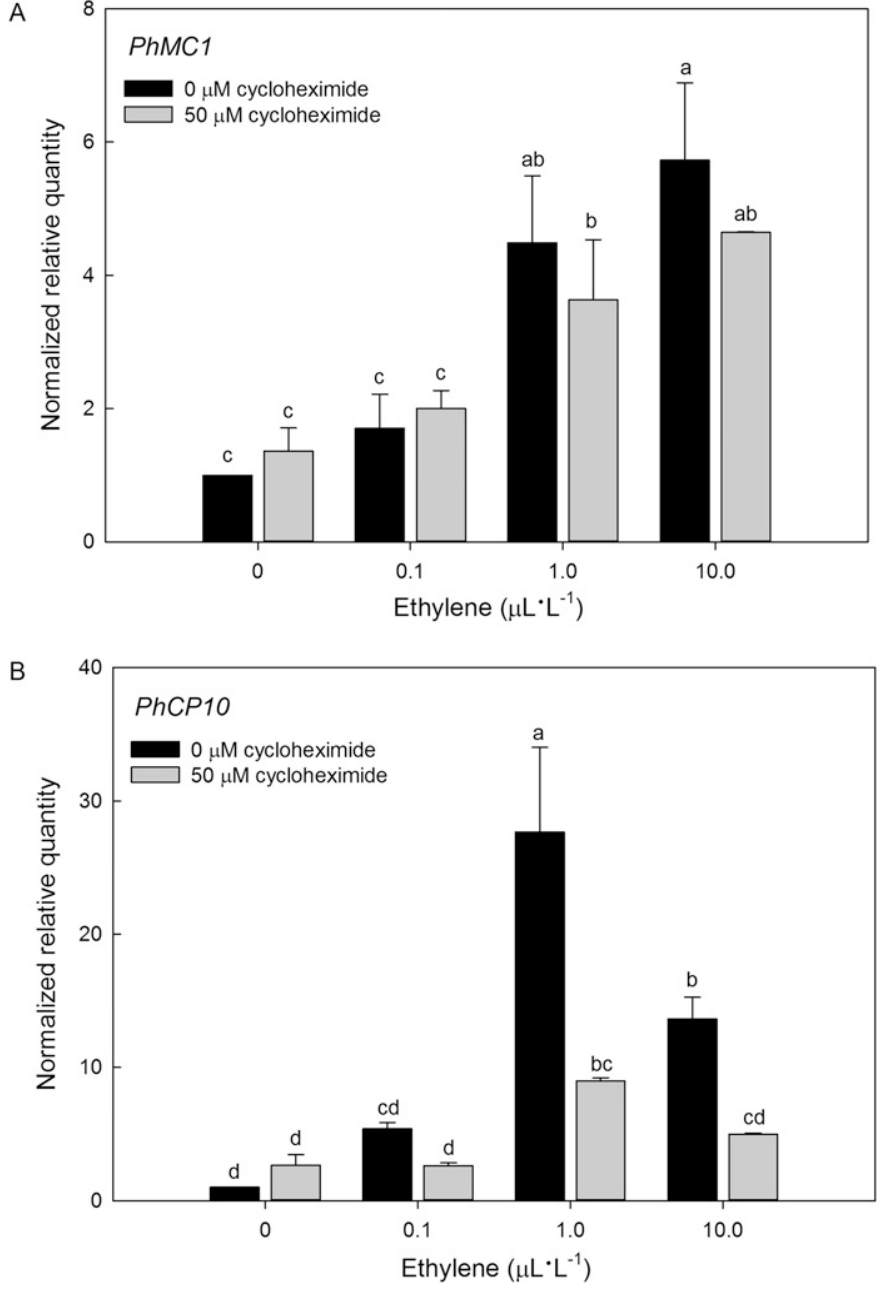

Fig. 4. Gene expression was analyzed in Petunia $\times$ hybrida 'Mitchell Diploid' petals from flowers treated with ethylene following pretreatment with cycloheximide or water. Detached flowers were treated with $0,0.1,1.0$, or $10.0 \mu \mathrm{L} \cdot \mathrm{L}^{-1}$ ethylene for $4 \mathrm{~h}$ after pretreating with either 0 (water) or $50 \mu \mathrm{M}$ cycloheximide for $3 \mathrm{~h}(n=6)$. Transcript levels of (A) PhMCl and (B) $P h C P 10$ (mean $\pm \mathrm{SD}, n=3$ ) in petals. Relative mRNA abundance compared with two reference genes (PhACTIN and PhRPS13) was determined by reverse transcription quantitative polymerase chain reaction. Different letters represent statistically significant difference between the means $(P \leq 0.05)$.

(anthesis), fully open flowers (nonsenescing), and senescing flowers (Fig. 5). GRRase activity increased 2.5-fold in the nonsenescing petals and 7-fold in the senescing petals when compared with the low level of activity detected in petals on the day of flower opening.

PhMC1 RNAi transgenic petunias have aCCelerated PETAL SENESCENCE. To investigate the functional role of PhMCl in petal senescence, gene expression was downregulated in transgenic petunias using RNAi. Under optimal greenhouse growing conditions, PhMCl RNAi transgenic plants had no obvious vegetative phenotypes (data not shown). Plants from three independent lines of the $T_{2}$ generation were analyzed for flower longevity phenotypes (Fig. 6). Flower longevity was evaluated in naturally senescing (i.e., unpollinated) corollas, and the time from anthesis to corolla wilting was reduced by $\approx 2 \mathrm{~d}$ in PhMC1 RNAi transgenics (Fig. 6A). Average corolla longevity for MD flowers in these experiments was $9.7 \mathrm{~d}$, whereas the longevity of F05-53, F05-6, and F05-65 corollas

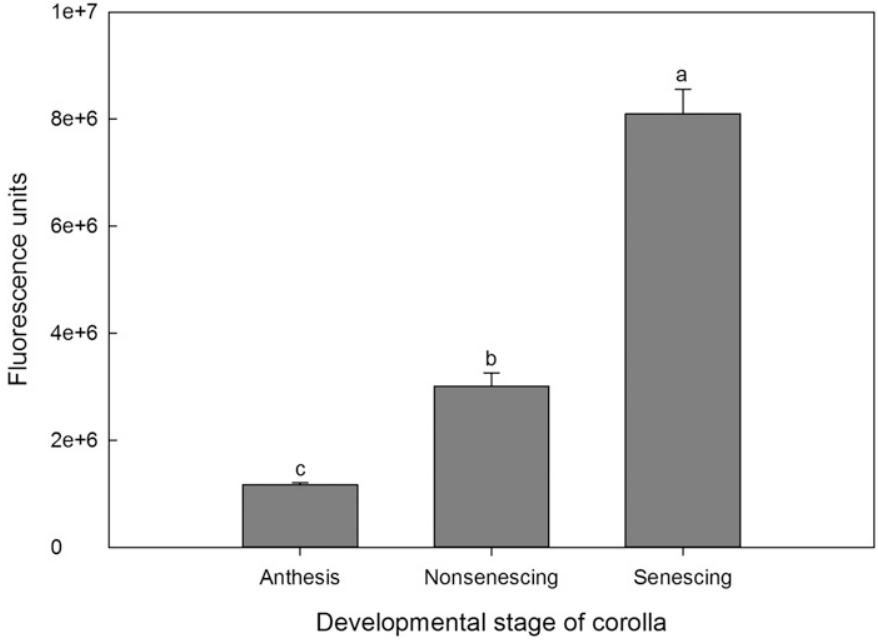

Fig. 5. Metacaspase-like activity was quantified in Petunia $\times$ hybrida 'Mitchell Diploid' petals. Activity against the fluorogenic metacaspase substrate BocGRR-AMC was analyzed in total petal protein extracts from three flower developmental stages (anthesis, nonnsenescing, and senescing). Fluorescence units are reported and bars represent the mean $\pm \mathrm{SD}(n=3)$. Different letters represent statistically significant difference between the means $(P \leq 0.05)$.

was 7.9, 7.8, and $6.9 \mathrm{~d}$, respectively. In senescing petals (at $48 \mathrm{~h}$ after pollination), PhMC1 transcript levels were reduced by $30 \%$ to $96 \%$ in the transgenic lines compared with wild type MD petals (Fig. 6B).

\section{Discussion}

Metacaspases are key regulators of cell death in plants, and as such, they play an integral role during development and in response to biotic and abiotic stresses (Coll et al., 2010; He et al., 2008; Hoeberichts et al., 2003; Tsiatsiani et al., 2011; Vercammen et al., 2007; Watanabe and Lam, 2011). Sequence and structural similarities support the conclusion that PhMC1 encodes a type I metacaspase (Supplemental Fig. 1; Table 2). RT-qPCR showed that PhMC1 transcript abundance increased during petal senescence in both pollinated and unpollinated flowers (Figs. 2 and 3). The expression pattern was similar to that of the senescence-related marker PhCP10 (Jones et al., 2005). We confirmed that the PhMC1 recombinant protein had activity against the metacaspase substrate GRR, which was inhibited by the arginal protease inhibitor, leupeptin (Fig. 1). Leupeptin has been shown to be a potent inhibitor of the arabidopsis metacaspases (Vercammen et al., 2004; Watanabe and Lam, 2005). Like PhMC1, most metacaspases that have been characterized have a neutral to slightly basic $\mathrm{pH}$ optimum (Bozhkov et al., 2005; He et al., 2008; Vercammen et al., 2004). Flower senescence in petunia was also accompanied by an increase in metacaspase-like activity (GRRase activity) in the corollas (Fig. 5).

The activity of some plant metacaspases is regulated posttranslationally, but the transcriptional regulation of gene expression also modulates metacaspase activity during plant development (Belenghi et al., 2007; Lam and Zhang, 2012; Wen et al., 2013; Zhang and Lam, 2011). In Picea abies (norway spruce), mcII-Pa is an essential component of the cell death machinery in the developing embryo (Bozhkov et al., 2005; Suarez et al., 2004). McII-Pa is expressed in the embryo suspensor cells during early embryogenesis and in the 
A
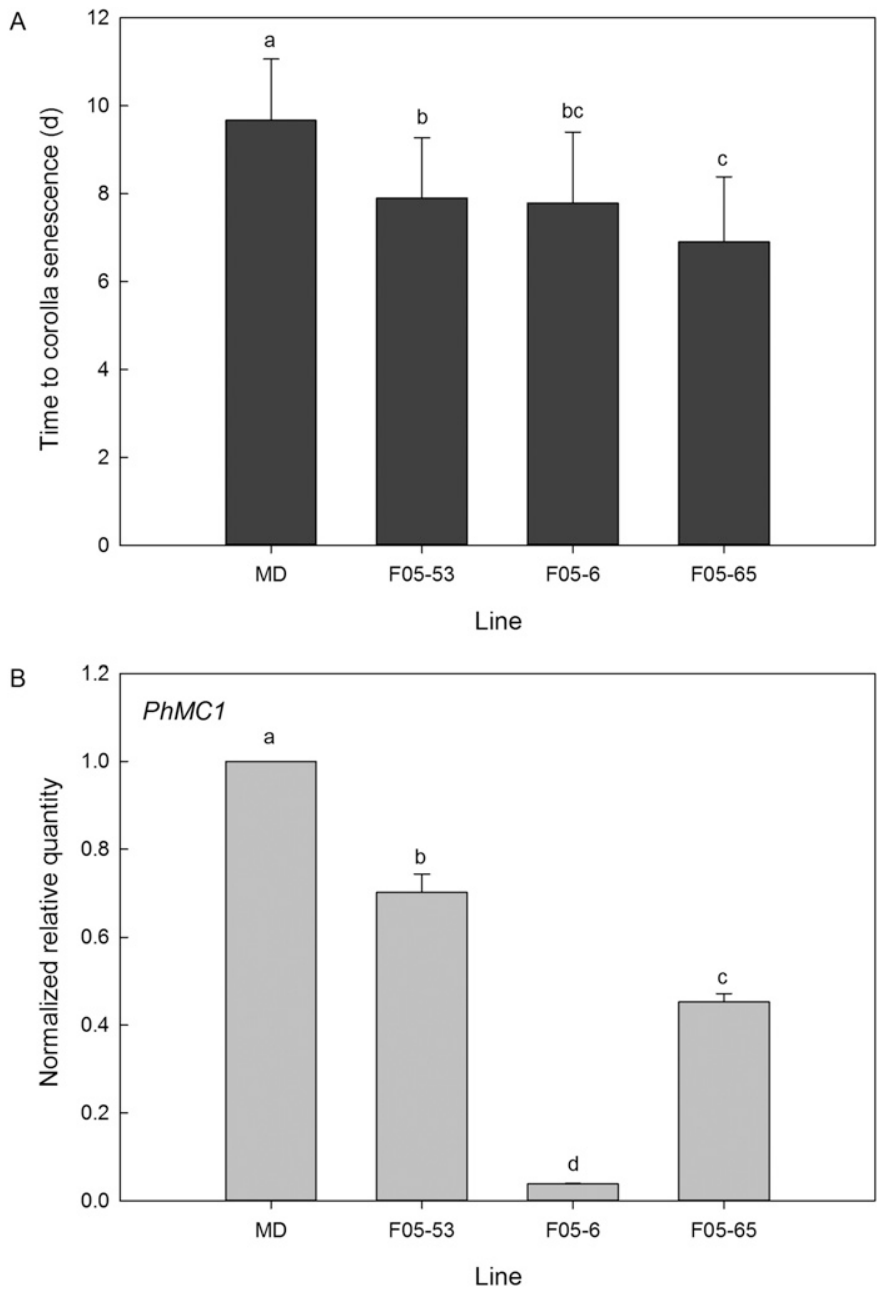

Fig. 6. Corolla senescence was evaluated in Petunia $\times$ hybrida PhMC1 RNAi transgenic lines. The time to flower senescence and $P h M C l$ gene expression were evaluated in $\mathrm{T}_{2}$ plants from three independent transgenic lines (F05-53, F05-6, and F05-65) compared with 'Mitchell Diploid' (MD, wild type). (A) Flower longevity was determined as the time from flower opening (anthesis) until corolla wilting in unpollinated, naturally senescing flowers $(n=15)$. (B) Relative gene expression of $P h M C 1$ in corollas at $48 \mathrm{~h}$ after pollination $(n=3)$ was determined by reverse transcription quantitative polymerase chain reaction. Transcript levels are expressed relative to PhACTIN and PhRPS13. Bars represent mean $\pm \mathrm{SD}$, and different letters represent statistically significant difference between the means $(P \leq 0.05)$.

procambial strands during xylem differentiation (Böllhoner et al., 2013; Suarez et al., 2004). It is involved in the execution of nuclear disassembly in cells destined for elimination during embryo development (Bozhkov et al., 2005). In grape, four of the six metacaspases show tissue-specific expression (Zhang et al., 2013). VvMC6 is expressed in floral tissue with very low levels detected in other organs. Zhang and colleagues (2013) conclude that this type II metacaspase ( $V v M C \sigma)$ might have a role in flower formation and ovule development in grape. The expression of $V v M C 1, V v M C 3$, and $V v M C 4$ increases during endosperm abortion in seedless grapes, and these metacaspases may be involved in PCD and disassembly of aborted ovules during stenospermocarpy (Zhang et al., 2013). The programmed senescence of petals allows the plant to remobilize nutrients from dying to developing tissues such as the seeds (Bai et al., 2010; Chapin and Jones, 2007, 2009; Jones et al., 2009). Gene expression patterns suggest that PhMC1 may have a role in the programmed degradation of the corolla during flower senescence.

Like the senescence-associated cysteine protease $P h C P 10$, PhMC1 expression was induced in petals by exogenous ethylene treatment (Fig. 4). Ethylene and other plant hormone signaling leads to the rapid protein synthesis-independent induction of primary response genes, also called immediateearly genes, and the later induction of protein synthesisdependent secondary response genes. Many primary response genes are induced within minutes of a stimulus, but some have delayed kinetics, and they are referred to more specifically as delayed primary response genes. A great majority of the early induced primary response genes encode transcription factors, whereas delayed primary response genes usually encode other proteins in the genome (Tullai et al., 2007). The loss of fresh weight and petal inrolling that accompanies flower senescence in Dianthus caryophyllus (carnation) is prevented by pretreatment with the protein synthesis inhibitor cycloheximide (Wulster et al., 1982). Similarly, cycloheximide prevents petal abscission in pollinated Pelargonium $\times$ hortorum (geranium) flowers (Hilioti et al., 2000). These studies show that the normal progression of ethylene-induced petal senescence (both wilting and abscission) requires protein synthesis.

In arabidopsis, the induction of $S A G 12$ by ethylene is agedependent (Grbic and Bleecker, 1995). AtSAG12 transcription is regulated directly by developmentally controlled senescence pathways, and the response to ethylene is secondary (Noh and Amasino, 1999). The upregulation of $P h C P 10$ was prevented by pretreating the flowers with cycloheximide (Fig. 4B). Similar to the regulation of AtSAG12, the induction of PhCP10 is a secondary response to the ethylene stimulus. By contrast, we found that $P h M C 1$ expression was a primary response to ethylene, which did not require de novo protein synthesis, and was therefore not inhibited by cycloheximide (Fig. 4A). Because PhMCl does not encode a transcriptional regulator, it may be functioning as a late primary response gene rather than an early primary response gene. This would be more consistent with its upregulation during the later stages of petal senescence and a role in mediating senescence timing.

Metacaspase genes from multiple plants have been shown to be differentially regulated by plant hormones including abscisic acid, salicylic acid, jasmonic acid, and ethylene (Huang et al., 2015; Liu et al., 2016a, 2016b). The amino acid sequence of PhMC1 is closest to that of tomato metacaspases SIMC6 (78\% identical) and SIMC5 (74\% identical). SlMC5 and SlMC6 transcripts increase during leaf senescence, and these genes are also upregulated by ethylene treatment (Liu et al., 2016b). Two of eight metacapases characterized from rice show increased expression after treatment with 1-aminocyclopropane1-carboxylic acid (ACC, the precursor to ethylene) (Huang et al., 2015). Although many articles report expression of metacapase gene family members in flowers, none have specifically investigated expression in senescing petals or ethylene treated flowers (Kwon and Huang, 2013; Liu et al., 2016b; Zhang et al., 2013).

A recent study by Coll et al. (2014) suggests a model by which AtMC1 and autophagy pathways are functioning in parallel to positively regulate HR-induced cell death in young tissues and negatively regulate senescence in older tissues. Similar to the autophagy deficient mutants, they report that atmcl mutants have premature senescence and are hypersensitive to ROS (Coll et al., 2014). The prosurvival function of 
AtMC1 may be due to its role in protein aggregate clearance during senescence. The atmcl plants overaccumulate insoluble protein aggregates as they age, which may lead, in part, to their premature senescence. PhMCl-deficient transgenic petunias also had an early flower senescence phenotype, evidenced by premature corolla wilting. PhMC1 may similarly function as a negative regulator of senescence in petunias. After pollination or age-related cues, the expression of PhMC1 may be needed to coordinate the timely senescence of petals and allow for complete cellular dismantling and remobilization of components from the petals before the final collapse or abscission of the corolla (Chapin and Jones, 2007). A recent search of the Petunia inflata and Petunia axillaris genome databases at SGN has identified four putative metacaspases (Fernandez-Pozo et al., 2015). This research lays the foundation for further work characterizing additional metacaspase family members in petunia.

\section{Literature Cited}

Ahmad, R., Y. Zuily-Fodil, C. Passaquet, O. Bethenod, R. Roche, and A. Repellin. 2012. Ozone and aging up-regulate type II metacaspase gene expression and global metacaspase activity in the leaves of field-grown maize (Zea mays L.) plants. Chemosphere 87:789-795.

Bai, S., B. Willard, M. Kinter, L.J. Chapin, A. Stead, and M.L. Jones. 2010. Proteomic analysis of post-pollination senescence. J. Expt. Bot. 61:1089-1109.

Belenghi, B., M.C. Romero-Puertas, D. Vercammen, A. Brackenier, D. Inze, M. Delledonne, and F. van Breusegem. 2007. Metacaspase activity of Arabidopsis thaliana is regulated by S-nitrosylation of a critical cysteine residue. J. Biol. Chem. 282:1352-1358.

Beers, E.P. and J.M. McDowell. 2001. Regulation and execution of programmed cell death in response to pathogens, stress and developmental cues. Curr. Opin. Plant Biol. 4:561-567.

Böllhoner, B., B. Zhang, S. Stael, N. Denance, K. Overmyer, D. Goffner, F. van Breusegem, and H. Tuominen. 2013. Post mortem function of AtMC9 in xylem vessel elements. New Phytol. 200:498510 .

Bozhkov, P.V., M.F. Suarez, L.H. Filonova, G. Daniel, A.A. Zamyatnin, S. Rodriguez-Nieto, B. Zhivotovsky, and A. Smertenko. 2005. Cysteine protease mcII-Pa executes programmed cell death during plant embryogenesis. Proc. Natl. Acad. Sci. USA 102:14463-14468.

Chapin, L.J. and M.L. Jones. 2007. Nutrient remobilization during pollination-induced corolla senescence in petunia. Acta Hort. 755:181190.

Chapin, L.J. and M.L. Jones. 2009. Ethylene regulates phosphorus remobilization and expression of a phosphate transporter (PhPT1) during petal senescence in petunia. J. Expt. Bot. 60:2179-2190.

Coll, N.S., A. Smidler, M. Puigvert, C. Popa, M. Valls, and J.L. Dangl. 2014. The plant metacaspase AtMC1 in pathogen-triggered programmed cell death and aging: Functional linkage with autophagy. Cell Death Differ. 21:1399-1408.

Coll, N.S., D. Vercammen, A. Smidler, C. Clover, F. Van Breusegem, J.L. Dangl, and P. Epple. 2010. Arabidopsis type I metacaspases control cell death. Science 330:1393-1397.

Fagundes, D., B. Bohn, C. Cabreira, F. Leipelt, N. Dian, M.H. Bodanese-Zanettini, and A. Cagliari. 2015. Caspases in plants: Metacaspase gene family in plant stress responses. Funct. Integr. Genomics 15:639-649.

Fernandez-Pozo, N., N. Menda, J.D. Edwards, S. Saha, I.Y. Tecle, S.R. Strickler, A. Bombarely, T. Fisher-York, A. Pujar, H. Foerster, A. Yan, and L.A. Mueller. 2015. The sol genomics network (SGN) - From genotype to phenotype to breeding. Nucleic Acids Res. 43:D1036-D1041. Fischer, U., R.U. Janicke, and K. Schulze-Osthoff. 2003. Many cuts to ruin: A comprehensive update of caspase substrates. Cell Death Differ. 10:76-100.
Grbic, V. and A.B. Bleecker. 1995. Ethylene regulates the timing of leaf senescence in arabidopsis. Plant J. 8:595-602.

He, R., G.E. Drury, V.I. Rotari, A. Gordon, M. Willer, T. Farzaneh, E.J. Woltering, and P. Gallois. 2008. Metacaspase- 8 modulates programmed cell death induced by ultraviolet light and $\mathrm{H}_{2} \mathrm{O}_{2}$ in arabidopsis. J. Biol. Chem. 283:774-783.

Hellemans, J., G. Mortier, A. De Paepe, F. Speleman, and J. Vandesompele. 2007. qBase relative quantification framework and software for management and automated analysis of real-time quantitative PCR data. BMC Genome Biol. 8:R19.

Hilioti, Z., C. Richards, and K.M. Brown. 2000. Regulation of pollination-induced ethylene and its role in petal abscission of Pelargonium $\times$ hortorum. Physiol. Plant. 109:322-332.

Hoeberichts, F.A., A. ten Have, and E.J. Woltering. 2003. A tomato metacaspase gene is upregulated during programmed cell death in Botrytis cinerea-infected leaves. Planta 217:517-522.

Huang, L., H. Zhang, Y. Hong, S. Liu, D. Li, and F. Song. 2015. Stressresponsive expression, subcellular localization and protein-protein interactions of the rice metacaspase family. Intl. J. Mol. Sci. 16:16216-16241.

Jones, M.L., G.S. Chaffin, J.R. Eason, and D.G. Clark. 2005. Ethylenesensitivity regulates proteolytic activity and cysteine protease gene expression in petunia corollas. J. Expt. Bot. 56:2733-2744.

Jones, M.L., A.D. Stead, and D.G. Clark. 2009Petunia flower senescence, p. 301-324. In: T. Gerats and J. Strommer (eds.). Petunia: A model system for comparative research. Springer, New York, NY.

Jorgensen, R.A., P.D. Cluster, J. English, Q. Que, and C.A. Napoli. 1996. Chalcone synthase cosuppression phenotypes in petunia flowers: Comparison of sense vs. antisense constructs and singlecopy vs. complex T-DNA sequences. Plant Mol. Biol. 31:957-973.

Kim, S.-M., C. Bai, S.-K. Oh, and D. Choi. 2013. A pepper (Capsicum annuum L.) metacaspase 9 ( $\mathrm{Camc} 9$ ) plays a role in pathogen-induced cell death in plants. Mol. Plant Pathol. 14:557-566.

Kwon, S.I. and D.J. Huang. 2013. Expression analysis of the metacaspase gene family in Arabidopsis. J. Plant Biol. 56:391-398.

Lam, E. and Y. Zhang. 2012. Regulating the reapers: Activating metacaspases for programmed cell death. Trends Plant Sci. 17:487494.

Liu, H., Z. Deng, J. Chen, S. Wang, L. Hao, and D. Li. 2016a. Genomewide identification and expression analysis of the metacaspase gene family in Hevea brasiliensis. Plant Physiol. Biochem. 105:90-101.

Liu, H., J. Liu, and Y. Wei. 2016b. Identification and analysis of the metacaspase gene family in tomato. Biochem. Biophys. Res. Commun. 479:523-529.

Mallona, I., S. Lischewski, J. Weiss, B. Hause, and M. Egea-Cortines. 2010. Validation of reference genes for quantitative real-time PCR during leaf and flower development in Petunia hybrida. BMC Plant Biol. 10:4.

NCBI Resource Coordinators. 2017. Database resources of the nation center for biotechnology information. Nucleic Acids Res. 45:D12D17.

Noh, Y.S. and R.M. Amasino. 1999. Identification of a promoter region responsible for the senescence-specific expression of SAG12. Plant Mol. Biol. 41:181-194.

Sievers, F., A. Wilm, D. Dineen, T.J. Gibson, K. Karpus, W. Li, R. Lopez, H. McWilliam, M. Temmert, J. Soding, J.D. Thompson, and D.G. Higgins. 2011. Fast, scalable generation of high quality protein multiple sequence alignments using Clustal Omega. Mol. Syst. Biol. 7:539.

Suarez, M., L.H. Filonova, A. Smertenko, E.I. Savenkov, D.H. Clapham, S. von Arnold, B. Zhivotovsky, and P.V. Bozhkov. 2004. Metacaspase-dependent programmed cell death is essential for plant embryogenesis. Curr. Biol. 14:339-340.

Tsiatsiani, L., E. Timmerman, P.-J. DeBock, D. Vercammen, S. Stael, B. van de Cotte, A. Staes, M. Goethals, T. Beunens, P. van Damme, K. Gevaert, and F. van Breusegem. 2013. The Arabidopsis METACASPASE9 degradome. Plant Cell 25:2831-2847.

Tsiatsiani, L., F. van Breusegem, P. Gallois, A. Zavialov, E. Lam, and P.V. Bozhkov. 2011. Metacaspases. Cell Death Differ. 18:1279-1288. 
Tullai, J.W., M.E. Schaffer, S. Mullenbrock, G. Sholder, S. Kasif, and G.M. Cooper. 2007. Immediate-early and delayed primary response genes are distinct in function and genome architecture. J. Biol. Chem. 282:23981-23995.

Uren, A.G., K. O'Rourke, L. Aravind, M.T. Pisabarro, S. Seshagiri, E.V. Koonin, and V.M. Dixit. 2000. Identification of paracaspases and metacaspases: Two ancient families of caspase-like proteins, one of which plays a key role in MALT lymphoma. Mol. Cell 6:961-967.

Vercammen, D., B. Belenghi, B. van de Cotte, T. Beunens, J.-A. Gavigan, R. de Rycke, A. Brackenier, D. Inzé, J.L. Harris, and F. van Breusegem. 2006. Serpin1 of Arabidopsis thaliana is a suicide inhibitor for metacaspase 9. J. Mol. Biol. 364:625-636.

Vercammen, D., W. Declercq, P. Vandenabeele, and F. van Breusegem. 2007. Are metacaspases caspases? J. Cell Biol. 179:375-380.

Vercammen, D., B. van de Cotte, G. de Jaeger, D. Eeckhout, P. Casteels, K. Vandepoele, I. Vandenberghe, J. van Beeumen, D. Inzé, and F. van Breusegem. 2004. Type II metacaspases Atmc4 and Atmc9 of Arabidopsis thaliana cleave substrates after arginine and lysine. J. Biol. Chem. 279:45329-45336.

Wang, X., X. Wang, H. Feng, C. Tang, P. Bai, G. Wei, L. Huang, and Z. Kang. 2012. TaMCA4, a novel wheat metacaspase gene functions in programmed cell death inducted by the fungal pathogen Puccinia striiformis F. sp. tritici. Mol. Plant Microbe Interact. 25:755-764.
Wang, L. and H. Zhang. 2014. Genomewide survey and characterization of metacaspase gene family in rice (Oryza sativa). J. Genet. 93:93-102.

Watanabe, N. and E. Lam. 2005. Two arabidopsis metacaspases AtMCP1b and AtMCP2b are arginine/lysine-specific cysteine proteases and activate apoptosis-like cell death in yeast. J. Biol. Chem. 280:14691-14699.

Watanabe, N. and E. Lam. 2011. Arabidopsis metacaspase $2 \mathrm{~d}$ is a positive mediator of cell death induced during biotic and abiotic stresses. Plant J. 66:969-982.

Wen, S., Q.M. Ma, Y.L. Zhang, J.P. Yang, G.H. Zhao, D.Q. Fu, Y.B. Luo, and G.Q. Qu. 2013. Biochemical evidence of key residues for the activation and autoprocessing of tomato type II metacaspase. FEBS Lett. 587:2517-2522.

Wulster, G., J. Sacalis, and H. Janes. 1982. The effect of inhibitors of protein synthesis on ethylene-induced senescence in isolated carnation petals. J. Amer. Soc. Hort. Sci. 107:112-115.

Zhang, Y. and E. Lam. 2011. Sheathing the swords of death: Posttranslational modulation of plant metacaspases. Plant Signal. Behav. 6:2051-2056.

Zhang, C., P. Gong, R. Wei, S. Li, X. Zhang, Y. Yu, and Y. Wang. 2013. The metacaspase gene family of Vitis vinifera L.: Characterization and differential expression during ovule abortion in stenospermocarpic seedless grapes. Gene 528:267-276. 
AtMC1

AtMC2

PhMC1

AtMC 3

AtMC 9

AtMC 8

AtMC 4

AtMC 7

AtMC5

AtmC 6

AtmC1

AtMC2

PhMC1

AtMC3

AtMC 9

AtMC8

AtMC 4

AtMC 7

AtMC 5

AtMC 6

AtMC1

AtmC2

PhMC1

AtMC3

AtMC 9

AtMC 8

AtMC 4

AtMC 7

AtMC5

AtMC 6

AtMC1

AtMC2

PhMC1

AtMC 3

AtMC 9

AtMC 8

AtMC 4

AtMC 7

AtMC5

AtMC 6

AtMC1

AtMC2

PhMC1

AtMC 3

AtMC 9

AtMC 8

AtMC 4

AtMC 7

AtMC 5

AtMC 6

MYPPPPSSIYAPPMLVNCSGCRTPLQLPSGARS IRCALCQAVTHIADPRTA----------------MLLLVDCSSCRTPLHLPPGATRIRCAICHAFTLIAPEPRLQSHASASPF --------MDGRRYKCKWCGTKMAAP I GAPS I CCPRCQSVTELQPRNNNGYAKMAAPI ---------MASRREVRCRCGRRMWVQPDARTVQCSTCHTVTQLYSLVDIA--------
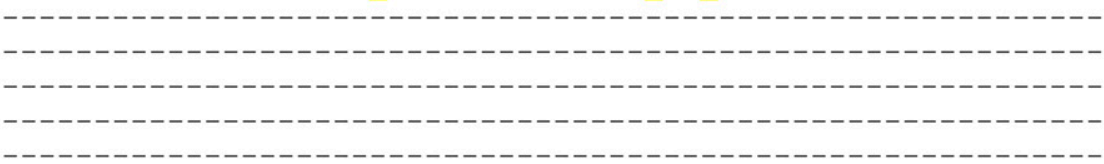

$\Delta \Delta$

$\Delta \Delta$

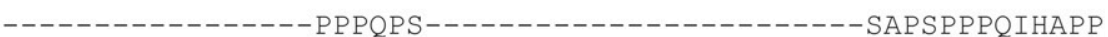
PFPNSSPAP---STFIYPPPTPSPYTHAPHAPSPENHAPPDSYPETHAPPASSPFNHAPP ANVVNNMINSAVNTGFYPAM----QGRIP-----NGN----NYQQ-------QP---QPF - RGAN-----RI I HGFQQLL----RQHQP-----QHH----EQQQQQMMAQPPP---RLL

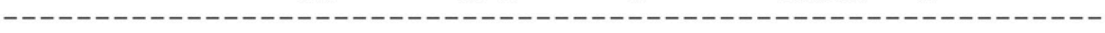
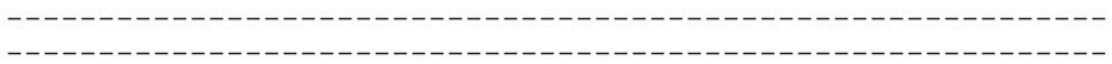

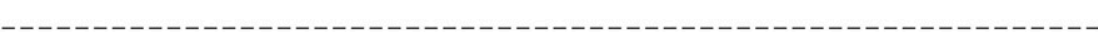

- - - - - - - - - - - - - - - - - - - - - - - - - - - - - - - - - - - - - - - - - - - - -

GQLPHPHGRKRAVICGISYRFSRHELKGCINDAKCMRHLLINKFKFSPDS I LMLTEEETD GPPPPVHGQKRAVIVGVSYKNTKDELKGCINDANCMKFMLMKRFQFPESCILMLTEEEAD MRPPAVHGRKRAVLCGITYRGHPKMLKGSVTDALSMRQLLVGKLGFPNASVVVLTEDEKD EPLPSPFGKKRAVLCGVNYKGKSYSLKGCISDAKSMRSLLVQQMGFP IDS ILMLTEDEAS MDQQGMVKKRLAVLVGCNYPNTRNELHGCINDVLAMKETILSRFGFKQDDIEVLTDEPE------MAKKALLIGINYPGTAVELRGCVNDVHRMQKCLIELYGFANKDIVIMIDTDK------MAKRALLIGINYPGTTEELQGCVNDVHRMHKCLVDRFGFAEEDITVLIDTDE------MTKKAVLIGINYPGTKAELRGCVNDVRRMYKCLVERYGFSEENITVLIDTDE------MAKKALLIGINYVGTKAELRGCVNDVRRMRISLVERYGFSEENIKMLIDTDS------MAKKAVLIGINYPGTKAELRGCVNDVRRVHKSLVDRFGFSERNITELIDTDE-

$$
:{ }^{*}: *^{*} \quad *:{ }^{*}:{ }^{*}: \text { : : } \quad * \quad: \quad: \text { : }
$$

PYRIPTKQNMRMALYWLVQGC--TAGDSLVFHYSGHGSRQRNYNG--DEVDGYDETLCPL PMRWPTKNNITMAMHWLVLSC--KPGDSLVFHFSGHGNNQMDDNG--DEVDGFDETLLPV PCKIPTKANIRSALRWLVQGC--QPGDSLVFFYSGHGTRVRDRDG--DEVDGHDESLCPV PQRIPTKRNIRKAMRWLVEGN--RARDSLVFHFSG SKVKPTGANIKAALRRMVDKAQAGSGDILFFHYSG SCIQPTGKNICDELDNLIASG--QSGDFLVFHYSG SYTQPTGKNIRQALSELIKPA--KSGDVLFVHYSG SSTQPTGKNIRRALADLVESA--DSGDVLVVHYS SSIKPTGKNIRQALLDLVEPA--KSGDVLFVHYSG SSTKPTGKNIRRALLNLVESA--KPGDVLVVHYS GTRVRDRDG--DEVDGHDESLCPV GTRIPSVKS--AHPFKQDEAIVPC GTRIPPGIEDSEDPTGFDECITPC GTRVPPETG-EEDDTGFDECIVPS GTRLPAETG-EDDDTGFDECIVPC GTRLPAETG-EDDDTGYDECIVPS GTRLPAETG-EDDDTGYDECIVPC $\star * \quad$ * : : : $\quad * \star \ldots: * \star \star \ldots *$. $\ldots *$ *

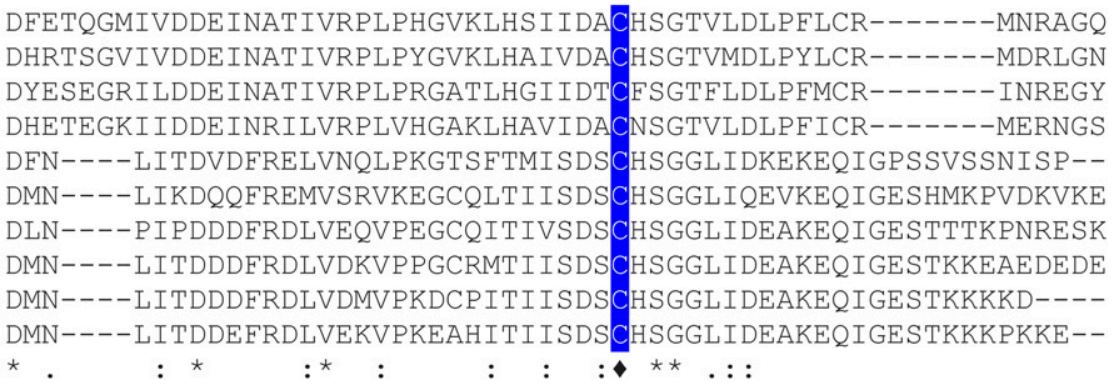

Supplemental Fig. 1. Multiple alignment of predicated metacaspase amino acid sequences from Petunia $\times$ hybrida PhMC1 (GenBank JQ314004) and Arabidopsis thaliana (Arabidopsis AtMC1-9; AtMC1, AY322525; AtMC2, AY322526; AtMC3, AY322527; AtMC 4, AY322528; AtMC5, AY322532; AtMC6, AY322533; AtMC7, AY322529; AtMC8, AY322530; AtMC9, AY322531. Cysteine residues in the zinc finger motif of the prodomain of type I metacaspases are indicated in yellow and by an open triangle $(\Delta)$. The putative histadine and cysteine catalytic residues are designated in dark blue and by a closed diamond $(\bullet)$. The second cysteine involved in activity and autolysis is green and indicated by a closed square $(\mathbf{\square})$. The lysine or arginine involved in the predicted autocatalytic cleavage site is pink and indicated by a closed circle (•). Sequence alignment was performed using Clustal Omega (1.2.4) multiple sequence alignment software (Larkin et al., 2007). Identical amino acids are indicated with as asterisk. Double dots indicate conserved substitutions and single dots indicate semi-conserved substitutions.

J. Amer. Soc. Hort. Sci. 142(5):1-2. 2017. 


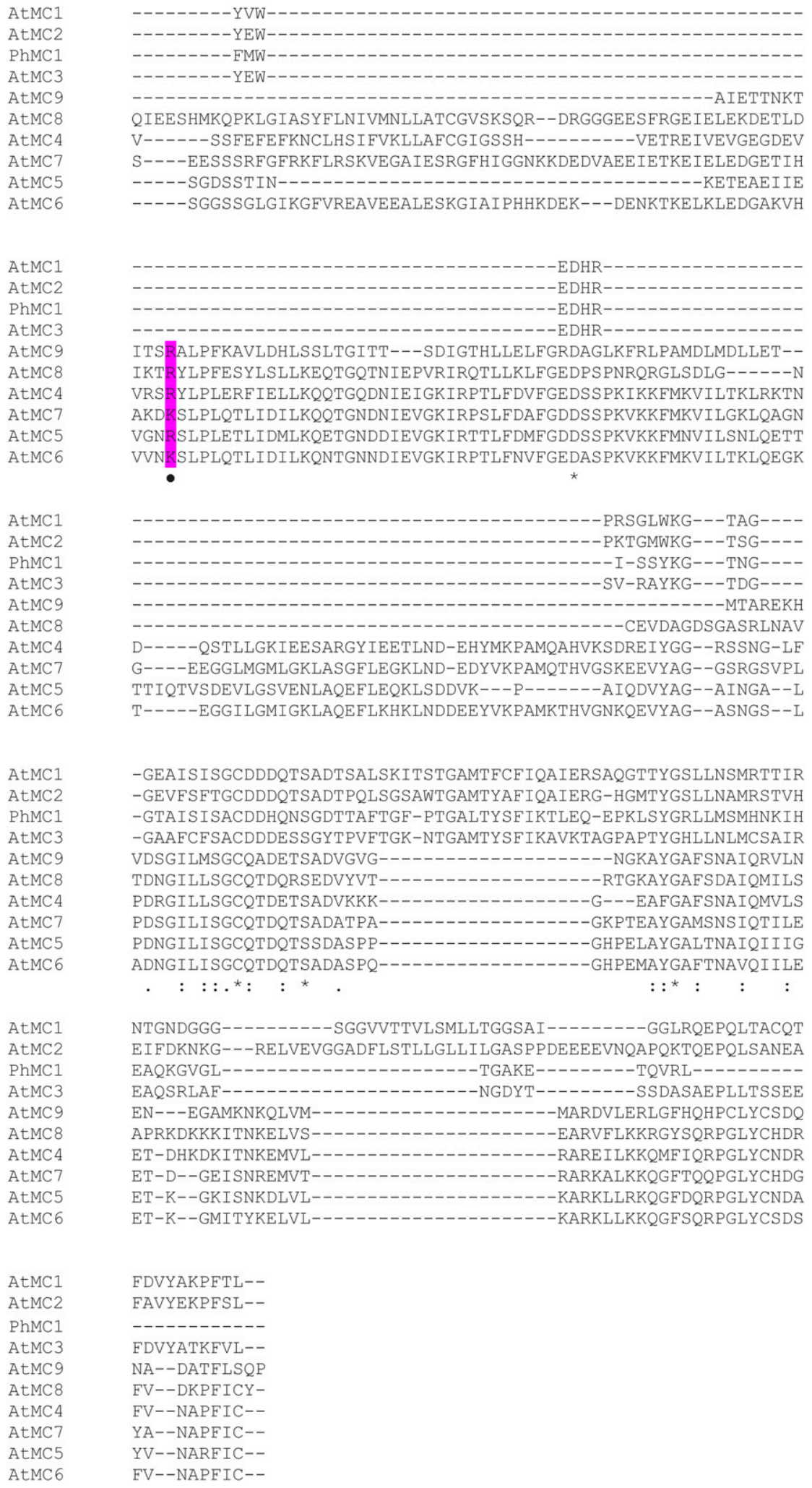

Supplemental Fig. 1. Continued. 